\title{
SEM STUDY OF GEMMULES AND SPICULES OF INDIAN TROCHOSPONGILLA LATOUCHIANA ANNANDALE AND Chinese T. Latouchiana Sinensis AnNandale (Porifera: DEMOSPONGIAE: SPONGILLINA: SPONGILLIDAE)
}

\author{
Shriraj S. Jakhalekar ${ }^{1} \&$ H.V. Ghate ${ }^{2}$ \\ 1,2 Post-Graduate Research Centre, Department of Zoology, Modern College of Arts, Science \& Commerce, \\ Shivajinagar, Pune, Maharashtra 411005, India \\ ${ }^{1}$ shriraj.jak@gmail.com, ${ }^{2}$ hemantghate@gmail.com (corresponding author)
}

Abstract: Gemmules and spicules of Trochospongilla latouchiana Annandale, 1907 from India and its subspecies T. Iatouchiana sinensis Annandale, 1919 from China have not been studied under SEM so far, as only optical microscopic illustrations are available. These illustrations are now provided using material from the Smithsonian Institution, USA. T. latouchiana sinensis has already been treated as a synonym of $T$. latouchiana. SEM observations reveal identical morphology of gemmules and spicules and it seems that synonymising the subspecies with $T$. latouchiana is justified, however more material must be studied to understand the variability of characters in these species.

Keywords: China, India, SEM, Spongillidae, Trochospongilla latouchiana, Trochospongilla latouchiana sinensis.

Genus Trochospongilla Vejdovsky, 1883 is one of the speciose and widespread genera of Spongillidae Gray, 1867. This genus presently includes 17 valid species (van Soest et al. 2014) and is distributed almost throughout the world, though most species are reportedly restricted to certain localities or zoogeographic areas (Penney \&
Racek 1968). Diagnostic characters of the genus are already given by Penney \& Racek (1968) and Manconi \& Pronzato (2002), and hence are not reiterated here.

T. latouchiana, as described by Annandale (1907, 1911), is a sponge that usually forms small, cushionshaped growths with minutely hispid surface and small inconspicuous oscula. Megascleres are entirely smooth, almost straight oxeas. Microscleres are absent. Gemmuloscleres are birotules with smooth and slender shaft, not projecting beyond the disc; rotules (circular discs) have entire margins, are flat or nearly flat, and unequal in diameter (Annandale 1907, 1911; Penney \& Racek 1968). The species T. latouchiana was described from a tank near the Indian Museum in Kolkata (formerly Calcutta), India. Apart from India, this species is distributed in regions like China, Southeast Asia, Japan and Australia (Annandale 1911; Penney \& Racek 1968; Racek 1969; Masuda \& Satoh 1989; Manconi \& Pronzato 2002; Masuda 2004; Manconi et al. 2013) but there are

\footnotetext{
DOI: http://dx.doi.org/10.11609/JoTT.04003.6269-77 | ZooBank: urn:Isid:zoobank.org:pub:E0AE7D64-C2DA-4FF8-A3C9-COFF7DBDF9AD

Editor: Cecilia Volkmer Ribeiro, Porto Alegre, Brazil.

Date of publication: 26 August 2014 (online \& print)

Manuscript details: Ms \# 04003 | Received 19 April 2014 | Final received 30 June 2014 | Finally accepted 22 July 2014

Citation: Jakhalekar, S.S. \& H.V. Ghate (2014). SEM study of gemmules and spicules of Indian Trochospongilla latouchiana Annandale and Chinese T. Iatouchiana sinensis Annandale (Porifera: Demospongiae: Spongillina: Spongillidae). Journal of Threatened Taxa 6(9): 6269-6277; http://dx.doi.org/10.11609/JoTT.o4003.6269-77

Copyright: @ Jakhalekar \& Ghate 2014. Creative Commons Attribution 4.0 International License. JoTT allows unrestricted use of this article in any medium, reproduction and distribution by providing adequate credit to the authors and the source of publication.

Funding: Self funded.

Competing Interest: The authors declare no competing interests.

Acknowledgements: The authors express their deepest gratitude to Dr. Klaus Rützler (Smithsonian Institution, USA), for providing sponge material used in this work and for reviewing the first draft of the manuscript. Without his support and encouragement this work would not have become possible. We are grateful to Mr. Swee Cheng Lim (National University of Singapore, Republic of Singapore) for helpful comments and for providing some essential literature. Dr. R. Sharma (then Officer-In-Charge, ZSI, Pune) kindly permitted access to the library at the Zoological Survey of India, Pune, and we thank him for that. We thank Professor and Head, Department of Physics, University of Pune, for providing the SEM facility and Mr. Suresh Shinde for excellent technical assistance and patience while doing SEM work. Many thanks to the people of Biodiversity Heritage Library who have digitized and made the classic taxonomy literature available online, and to Mr. Alan Hadley for developing a wonderful image-stacking free-ware, CombineZM. Finally we are indebted to the authorities of the Modern College for facilities and encouragement.
} 
no SEM illustrations (either of gemmules or spicules) of Indian material of this species, which appears to be rare and perhaps endangered now. After Annandale $(1907,1911)$, no worker seems to have seen or studied this species in India. Recent State Fauna of West Bengal (Pattanayak 1998) lists this species, but this inclusion is based on the literature only and no fresh material was available even from the type locality. Masuda \& Satoh (1989) and Masuda (2004) have worked on this species from Japan and Cambodia and have provided SEM images of diagnostic characters in Masuda \& Satoh (1989) but there appears some variation that needs further study (explained later).

Annandale (1919) also described a subspecies of $T$. latouchiana, namely $T$. latouchiana sinensis, from China; however, Gee (1932) expressed doubt about the validity of this subspecies, primarily due to great variation in spicule length and breadth. Penney \& Racek (1968), after studying more material, synonymised $T$. latouchiana sinensis with $T$. latouchiana (sensu stricto). However, these authors did not give SEM illustrations of T. latouchiana or its 'so-called' subspecies, hence this note is prepared.

\section{MATERIALS \& METHODS \\ Material Studied}

Following dry preserved sponges (museum material) were examined for this work. Small pieces of both these species were kindly provided by Dr. Klaus Rützler (Smithsonian Institution, USA)

(i) T. latouchiana - USNM \# 8657, Acc. No. 50044, Smithsonian Institution NMNH, USA. Loc. Museum Tank, Calcutta (now Kolkata), India, received originally from Indian Museum. (Type locality material and, perhaps, part of the Type Material).

(ii) T. latouchiana sinensis - USNM \# 30746, Acc. No. 338947, Smithsonian Institution NMNH, USA. Loc. Soochow, China. Coll. Gist Gee, N.; Identification by Smith, F.

As far as possible, while describing the characters of these species, we have followed the recent terminology provided by Boury-Esnault \& Rützler (1997) and Manconi \& Pronzato (2002)

\section{Methods}

Light Microscopy (LM) and Scanning Electron Microscopy (SEM): Spicules were isolated by standard nitric acid digestion method and permanent slides were prepared for LM study. For SEM study, spicules and gemmules were mounted on the stub, sputter-coated, and photographed using JEOL JSM - 6360A, as described earlier (Jakhalekar \& Ghate 2013). Photos of pieces of museum material were taken at different focusing planes using a stereo-zoom trinocular microscope (Leica MZ6) with a dedicated photography attachment (Canon Power Shot S50) and were digitally stacked using CombineZM. Digital LM and SEM images were processed using Adobe Photoshop CS5 Version 12.0, for clarity and contrast.

Morphometry of Spicules and Gemmules: Spicules were measured under LM with the help of calibrated ocular micrometer (Erma). Dimensions of spicules were further verified by comparing those with SEM images. Twenty-five spicules of each type from each material were measured and mean and the range of values were determined.

About 100 megascleres from each material were screened under LM and SEM for the presence of any tubercles or spinous processes.

Gemmules, being few in number, were measured by analyzing SEM images with Adobe Photoshop CS5. Diameter of 10 gemmules from each material was measured and mean and range of values were determined.

\section{OBSERVATIONS}

The skeleton of $T$. latouchiana is whitish in appearance. It has loose consistency with large cavities therein. Spicule fibres, as described by Annandale (1911) and Penney \& Racek (1968), are evident in the skeleton (Images 1A,B). Gemmules were found dispersed throughout in the sponge skeleton, in the small piece studied here (Images 1A \& B, 2A). T. latouchiana sinensis shows similar attributes for skeleton (Images 1C,D \& 2C).

Megascleres of $T$. latouchiana are straight to feebly curved, entirely smooth oxeas with sharply pointed tips (Images 2B, 4B). Megascleres of T. latouchiana sinensis have very similar morphology but most of these are rather slender and somewhat longer (Images 2D \& 4D) (Table 1).

Gemmuloscleres of $T$. latouchiana are very small birotules, with a smooth shaft, bearing almost flat discs at both the ends (Image 2B). The diameter of the entirely smooth shaft is maintained throughout its length, except at the very tips where it merges into discoid rotules. Shaft does not extend beyond rotules. Rotules are flat, circular discs with margins entire, distinctly recurved and bearing minute spines. Planes of rotules are at right angles to the axis of the shaft. Rotules of a single spicule are somewhat unequal in diameter. Upper (outer) rotule is smaller and shows relatively more number of marginal spines than the larger lower (inner) rotule; at 
higher magnification few spines are also visible on the surface of upper rotule (Images 3A,B \& 4A).

Gemmuloscleres of $T$. latouchiana sinensis are morphologically similar except for the measurements of shaft and rotules. Shaft is longer and rotules are smaller in diameter as compared with that of $T$. latouchiana (s.s.) (Images 2D \& 3C,D) (Table 1). Images 4A and 4C show surface of the upper rotule.

Gemmules of $T$. latouchiana were found throughout the skeleton, in the small piece studied (Images 1A \& 2A). These are very small and appear shining, pearly-white under LM (Image 1B). These are spherical structures with a distinct conical elevation at the gemmular foramen, and under SEM, show interesting surface sculpture formed by the upper rotules of radially arranged gemmuloscleres and the outer layer of gemmular wall (Image 5A). The elevated gemmular foramen is bordered by a collar made up of gemmuloscleres arranged at an angle (Image 5B). Gemmular wall consists of well developed inner, pneumatic and outer layers (Image 6A). The pneumatic layer, though well developed, is thin and distinctly cellular (i.e., made up of small globular cavities). These organised tiny spaces, made from spongin, are interconnected by small pores. Gemmuloscleres are radially embedded in the pneumatic layer and their arrangement is in monolayer. Smaller rotules form the outer surface whereas larger rotules rest on the inner layer of gemmular wall (Image $6 \mathrm{~B})$. At gemmular foramen the wall of gemmule is just raised and hence no distinguishable foraminal tube is visible. Mass of thesocytes can be seen in the cavity at the centre (Image 6A).

Gemmules of $T$. latouchiana sinensis are somewhat larger (Table 1), but almost identical in morphology to the gemmules of $T$. latouchiana (s.s.) (Images $1 C, D ; 2 C$; 5C,D; 6C,D). These appear to differ minutely from $T$. latouchiana (s.s.) in having a bit thicker pneumatic layer.

Measurement of spicules using LM and SEM
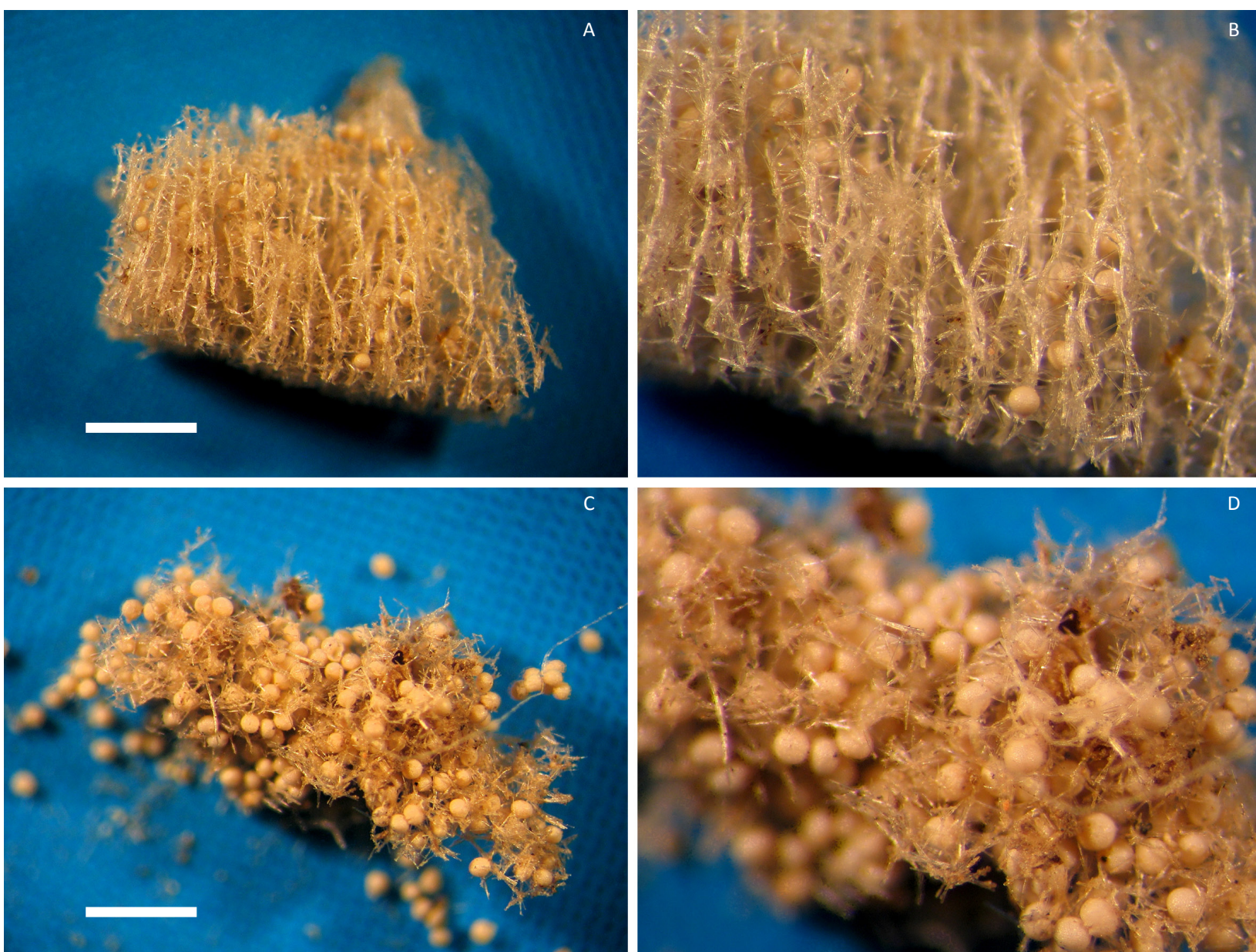

Image 1. LM images of small pieces of dry preserved sponge material.

A - T. latouchiana; B - Close-up of material in A. Note vertical spicular bundles and gemmules; C - T. latouchiana sinensis;

D - Close-up of material in C. (Scale: A \& C = 1mm). (C) H.V. Ghate \& Shriraj S. Jakhalekar 

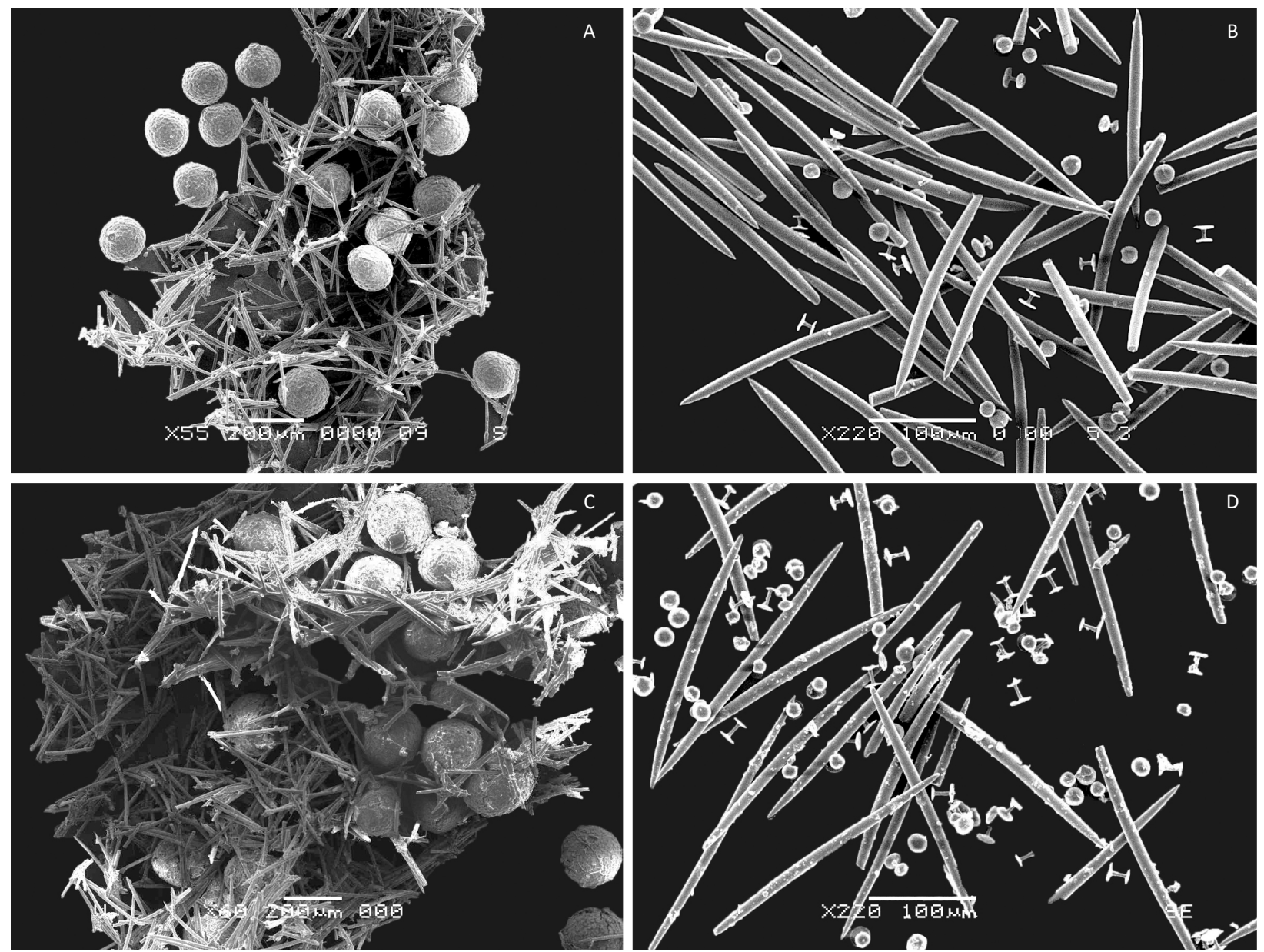

Image 2. SEM images of skeleton with gemmules, megascleres and gemmuloscleres.

A - Loose skeleton of T. Iatouchiana; B - Megascleres and gemmuloscleres of T. latouchiana; C - T. latouchiana sinensis spicular skeleton with interspersed gemmules; D - Megascleres and gemmuloscleres of $T$. latouchiana sinensis. Note the similarity in morphology but overall slenderness of spicules as compared with those of T. Iatouchiana. () H.V. Ghate, Shriraj S. Jakhalekar \& Shinde

Table 1. Comparison of ranges and means (given in parentheses) of measurements (in $\mu \mathrm{m}$ ) of spicules and gemmules of $T$. latouchiana and T. Iatouchiana sinensis. Values provided by Annandale (1907 \& 1919) and Penney \& Racek (1968) are also included.

\begin{tabular}{|c|c|c|c|c|c|c|}
\hline & & \multicolumn{3}{|c|}{ T. Iatouchiana Annandale, 1907} & \multicolumn{2}{|c|}{ T. Iatouchiana sinensis Annandale, 1919} \\
\hline & & $\begin{array}{l}\text { Smithsonian Sample } \\
\text { studied here }\end{array}$ & Annandale (1907) & $\begin{array}{c}\text { Penney \& Racek } \\
\text { (1968) }\end{array}$ & $\begin{array}{l}\text { Smithsonian Sample } \\
\text { studied here }\end{array}$ & Annandale (1919) \\
\hline \multirow{2}{*}{ Megasclere } & $\mathrm{L}$ & $200-248,(228.48)$ & $(280)$ & $220-310$ & $260-300,(280.08)$ & $220-310$ \\
\hline & B & $12-16,(12.24)$ & - & $11-16$ & $10-14,(11.84)$ & $10-12$ \\
\hline \multirow{5}{*}{ Gemmulosclere } & TL & $14-16,(15.84)$ & $(17.5)$ & $13-17$ & $18-20,(19.84)$ & $12-15$ \\
\hline & $S L$ & $8,(8)$ & - & - & $12-14,(12.16)$ & - \\
\hline & DLR & $18-20,(19.68)$ & \multirow{3}{*}{$(20)$} & $16-19$ & $12-20,(16.64)$ & $12-15$ \\
\hline & DSR & $14-18,(16.08)$ & & $13-16$ & $12-16,(12.64)$ & - \\
\hline & DS & $4,(4)$ & & $3-4$ & $2-4,(3.92)$ & - \\
\hline Gemmule & DG & $160-194,(176.26)$ & $(200)$ & $175-235$ & 200-229, (214.39) & $260-280$ \\
\hline
\end{tabular}

L - length of megasclere; B - breadth of megasclere; TL - total length of gemmulosclere; SL - shaft length of gemmulosclere, between the rotules;

DLR - diameter of larger (lower/inner) rotule; DSR - diameter of smaller (upper/outer) rotule; DS - diameter of shaft of gemmulosclere; DG - diameter of gemmule. 

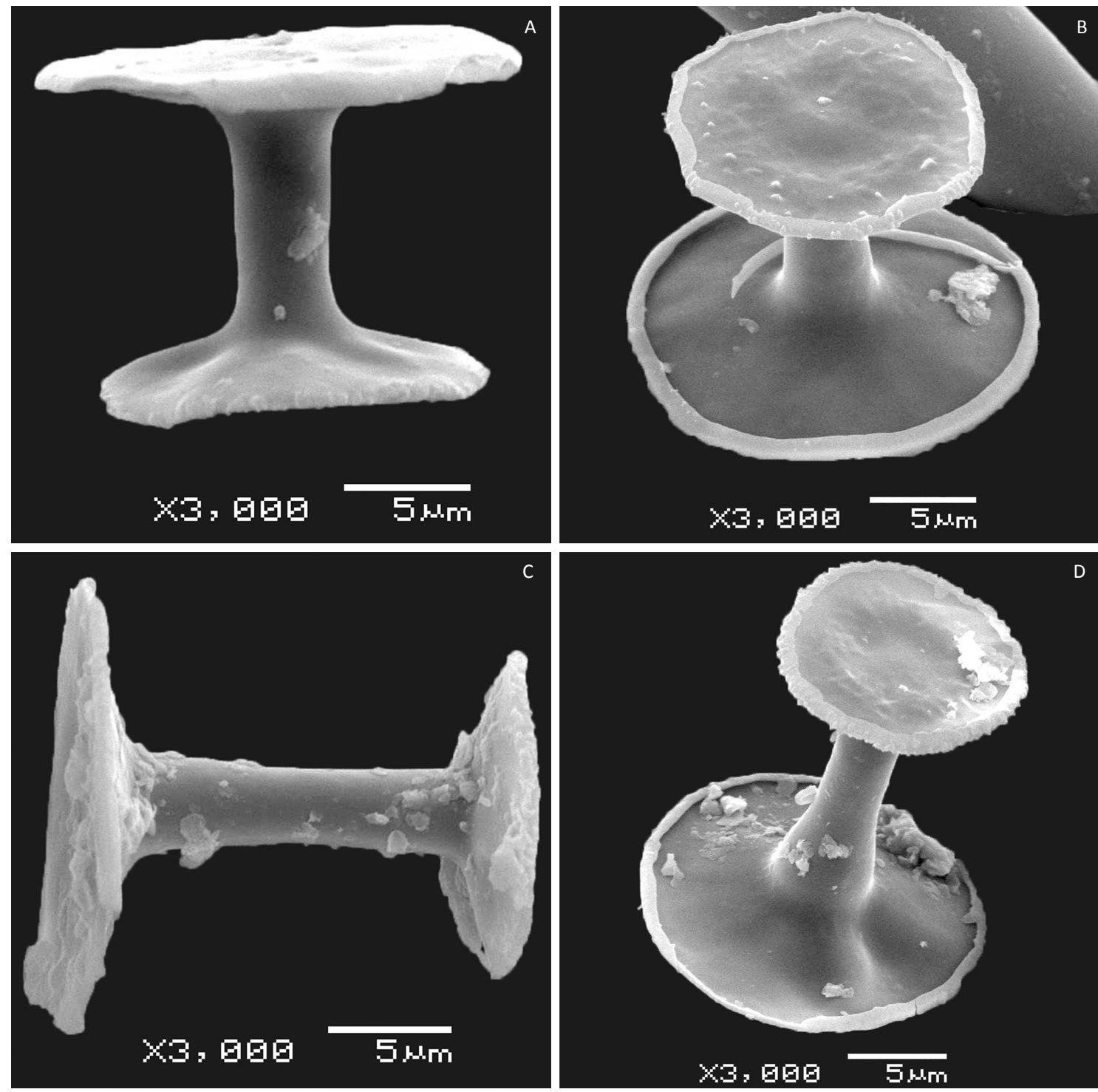

Image 3. Comparison of gemmuloscleres with SEM.

A - Lateral view of gemmulosclere of T. latouchiana; B - View at an angle of the gemmulosclere; C - Lateral view of gemmulosclere

of T. latouchiana sinensis; D - View at an angle of the gemmulosclere. Note spines on recurved margins. (C) H.V. Ghate, Shriraj S. Jakhalekar \& Shinde

reveal that the spicules of $T$. latouchiana sinensis are somewhat longer than those of $T$. latouchiana (s.s.). These measurements of spicules and gemmules of $T$. latouchiana (s.s.) and T. latouchiana sinensis are presented in Table 1, along with the values provided by Annandale (1907 \& 1919) and Penney \& Racek (1968).

\section{Discussion}

This is probably the first SEM study of gemmules and spicules of these two sponges from India and China. Our material of T. latouchiana (s.s.) and T. latouchiana sinensis were so small that we cannot really comment or infer anything regarding the variation present in spicules of T. latouchiana group. We have, however, depicted the morphology of diagnostic characters of $T$. latouchiana sinensis simultaneously with $T$. latouchiana (s.s.) at SEM level for better understanding. We have also provided the measurements of spicules and gemmules from the material made available to us. From this, we feel that there lies no significant morphological difference in the parent species and its subspecies, as the characters other than measurements of spicules, which were not dealt in depth previously, like gemmular shape and structure, nature of pneumatic layer, structure of gemmular foramen, are very conforming and show no great deal of structural variation. Overall slenderness 

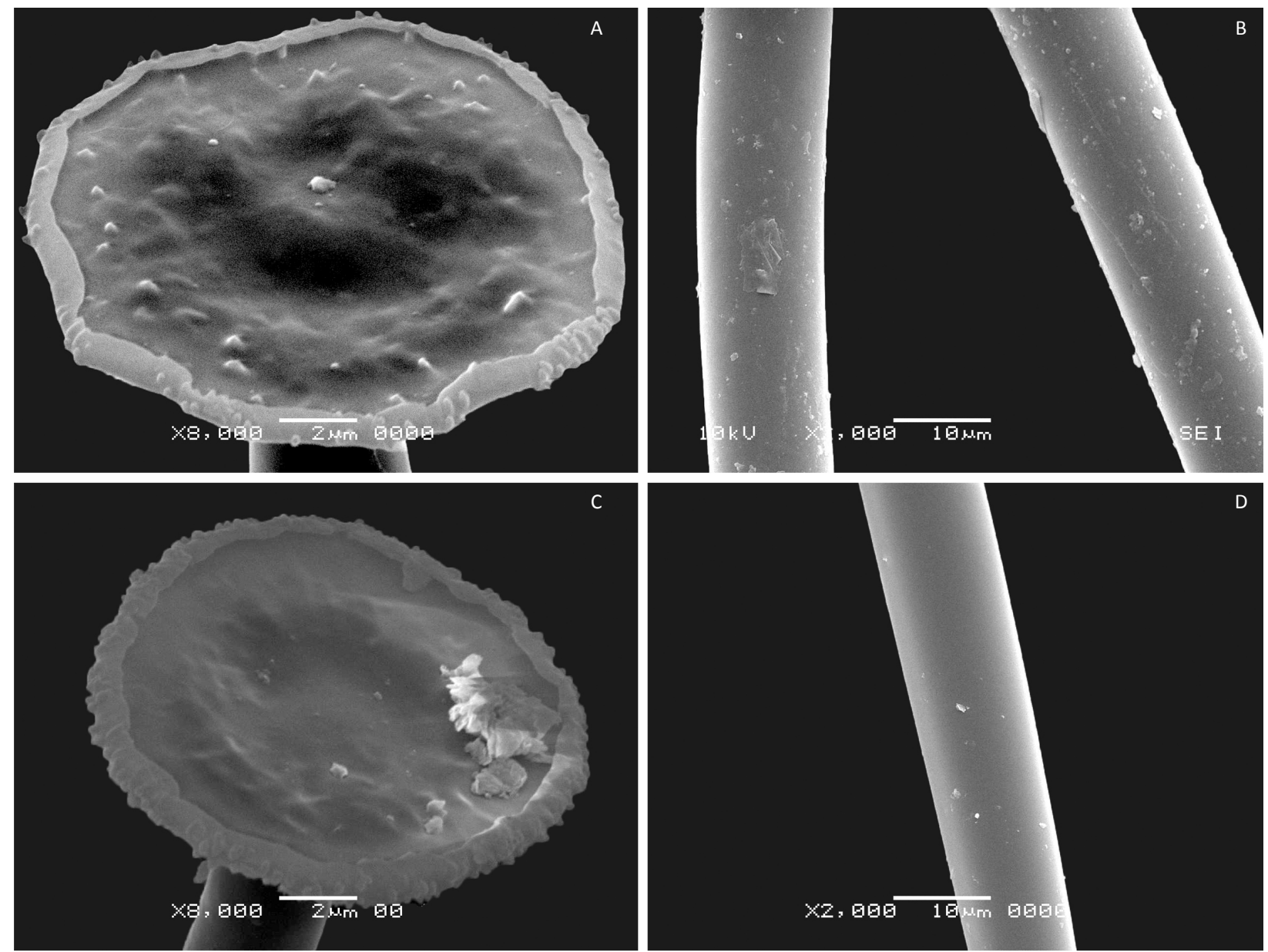

Image 4. Close-ups of upper rotules of gemmuloscleres and surface of megascleres.

A - Upper rotule of gemmulosclere of T. Iatouchiana; B - Megascleres of T. latouchiana showing smooth surface; C - Upper rotule of gemmulosclere of T. Iatouchiana sinensis; D - Smooth surface of megasclere of T. Iatouchiana sinensis. @ H.V. Ghate, Shriraj S. Jakhalekar \& Shinde

of spicules in T. latouchiana sinensis material made available to us can be observed but we refrain from commenting confidently on this topic. Fresh collection from the type localities of $T$. latouchiana (s.s.) and $T$. latouchiana sinensis are essential and might facilitate the molecular work on this problem.

Annandale's (1919) subspecies from China, $T$. latouchiana sinensis, validity of which was doubted by Gee (1932), remained in the state of ambiguity till Penney \& Racek (1968) synonymised it under T. latouchiana, pointing that the length of gemmuloscleres cannot be regarded as a decisive criterion, since these spicules in the $T$. latouchiana group vary to a great extent in terms of length and many variations can be found at a time in the same individual of this species. Our observations on the limited material at hand, support the views of Penney \& Racek (1968).

T. latouchiana is also reported from Australia (Racek
1969), Japan (Masuda \& Satoh 1989), and Cambodia (Masuda 2004). Racek (1969) illustrates the spicules by line drawings, Masuda \& Satoh (1989) by SEM, whereas Masuda (2004) gives LM images only. Our descriptions and illustrations, of spicules and gemmules of $T$. latouchiana, somewhat match with those provided by the above mentioned authors. However, the most striking difference exists in the surface of megascleres, which are absolutely smooth in our sample and spiny in samples from Australia, Cambodia and Japan.

Racek (1969) originally recorded spines on the surface of megascleres of Australian material of $T$. latouchiana. While reporting the spines in megascleres of that material, and comparing it with the typical form from Asia, Racek (1969) mentions (verbatim): "The megascleres of the Australian specimens are not always completely smooth as those recorded for the typical species from Asia, and a great number possess 

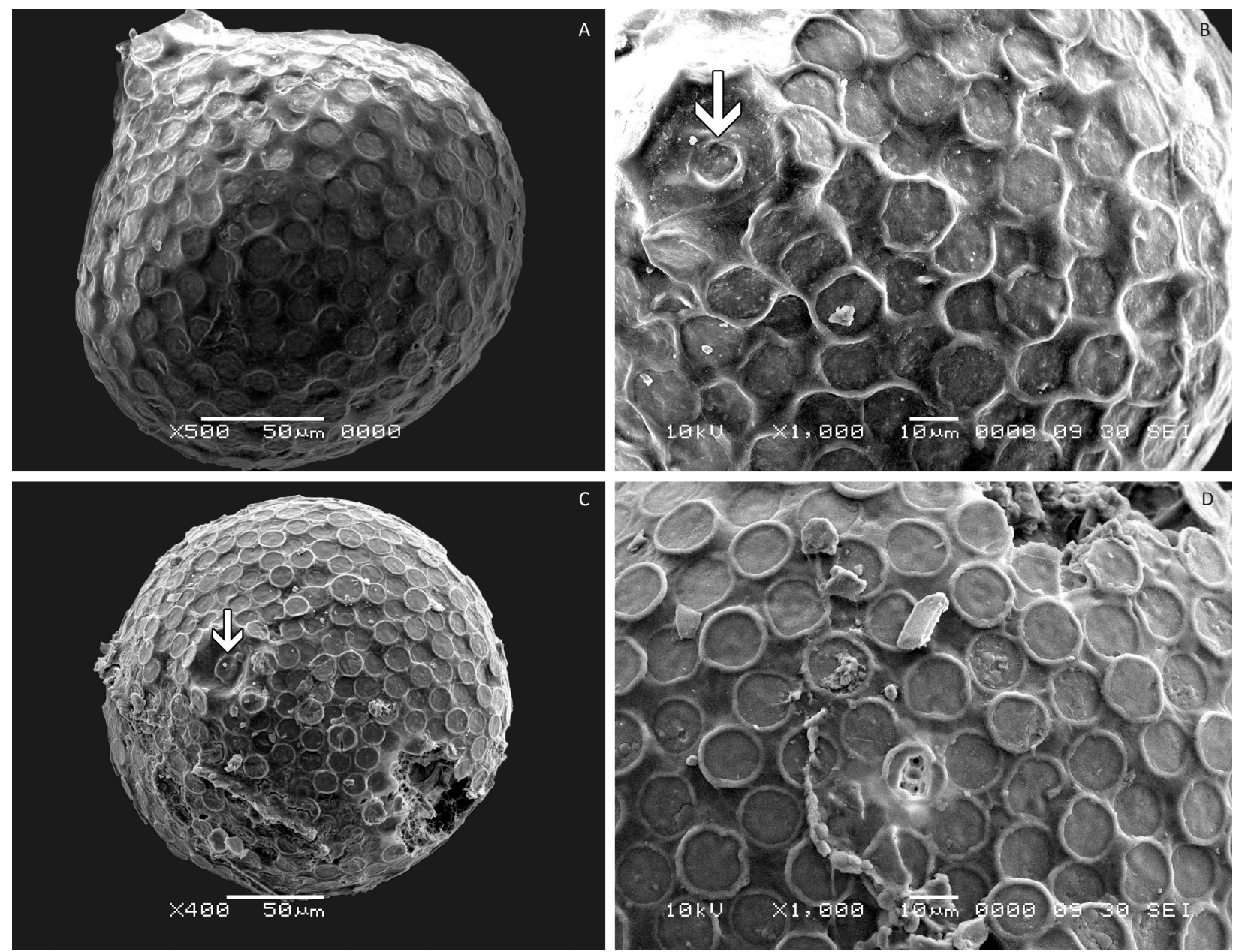

Image 5. Gemmules and close-ups of gemmular surface.

A - Gemmule of T. latouchiana; B - T. latouchiana: Gemmular foramen and surface of the gemmule. The raised gemmular foramen, shown here with an arrow, is collared by gemmuloscleres arranged at angles; C - Gemmule of $T$. latouchiana sinensis. Gemmular foramen is shown with an arrow; D - T. Iatouchiana sinensis: surface of the gemmule. @ H.V. Ghate, Shriraj S. Jakhalekar \& Shinde

incipient though clearly discernible spines. Even though such feebly spined megascleres have also been found by the author (means Racek) in the type slides examined, they are never as frequent as in the Australian material". However, in the illustrations provided by Racek (1969), there is just a single incipient spine and a couple of obscure structures shown on a megasclere, and the other megasclere is shown to be completely smooth. Masuda \& Satoh (1989) and Masuda (2004) subsequently reported the presence of such spinous megascleres in the material of T. latouchiana from Japan and Cambodia, respectively. Our material, collected from India and China, studied with LM and SEM, does not show any spines on the surface of megascleres, and hence these megascleres can be regarded as entirely smooth, as originally described by Annandale (1907, 1911) and Penney \& Racek (1968).

In the same paper, Racek (1969) describes another species of Trochospongilla, namely T. petrophila. This species is close to $T$. latouchiana and is characterised by high proportion of spinous megascleres and differences in measurements of gemmuloscleres. However, while describing T. petrophila, Racek (1969) also stated that there also exist, though rarely, entirely smooth megascleres. It is interesting to note that while discussing the closeness of $T$. petrophila with T. latouchiana, Racek (1969) comments a possibility that if 'trinominal nomenclature is introduced in freshwater sponge taxonomy in future, this species may be relegated to a subspecies of $T$. latouchiana'. $T$. petrophila has, however, retained its full-species status till date in the World Porifera Database (van Soest et al. 2014), possibly due to the paucity of work on Australian freshwater sponges after Racek.

The spinous megascleres from the samples of $T$. latouchiana from Australia (as per the description), 

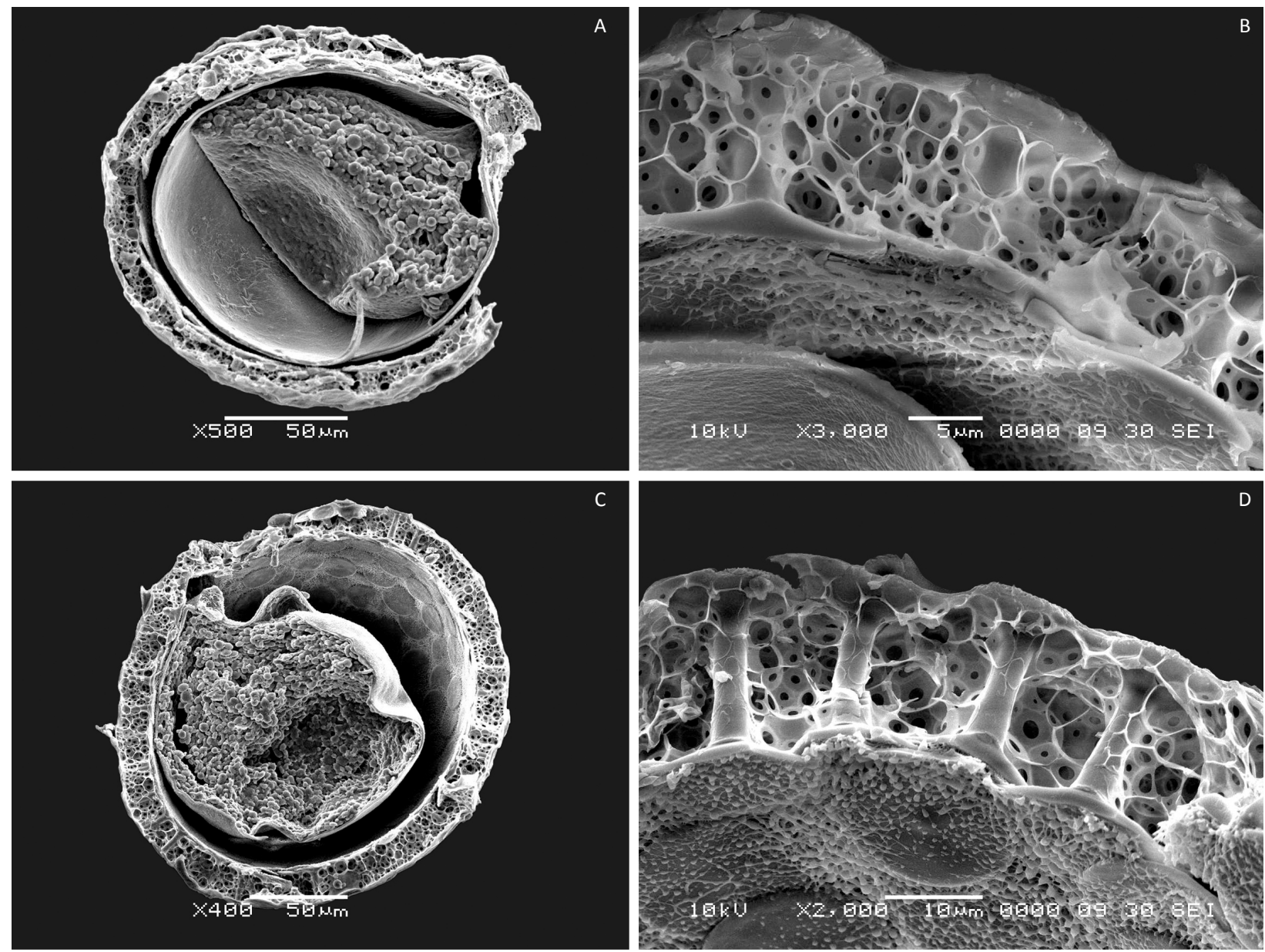

Image 6. Cut gemmules and close-ups of sections of gemmular walls.

A - T. Iatouchiana; B - Close-up of gemmular wall; C - T. Iatouchiana sinensis. Note the resemblance with that of T. Iatouchiana;

D - Close-up of gemmular wall of T. latouchiana sinensis. (C) H.V. Ghate, Shriraj S. Jakhalekar \& Shinde

Japan and Cambodia (as per the description and illustrations), resemble to those present in $T$. petrophila. The gemmuloscleres of $T$. petrophila also appear to be similar, in morphology, to those present in $T$. latouchiana; however, the rotules are somewhat smaller as compared to those of $T$. latouchiana from our material and those given by Annandale (1907), Penney \& Racek (1968) and Racek (1969). T. latouchiana group is known to vary in measurements of spicules (Penney \& Racek 1968), and so we feel some additional criteria (such as molecular work) are needed to delimit these species.

The material of $T$. latouchiana studied here, from the type locality, matches well with the original description and illustrations provided by Annandale (1907), and hence represents the typical form of the species. Similarity in spiny megascleres of $T$. latouchiana referred by Masuda \& Satoh (1989) and Masuda (2004) with those of T. petrophila as shown by Racek (1969) is intriguing.

Another problem is created by the checklist of Indian Freshwater Sponges, in which Soota (1991) synonymised $T$. latouchiana with an exclusively South American species of Trochospongilla, namely $T$. paulula (Bowerbank, 1863). This synonymy was also originally speculated by Gee (1932), based on the differing lengths of gemmuloscleres present in T. latouchiana (s.s.) and $T$. latouchiana sinensis but later Penney \& Racek (1968) ruled out the possibility of such synonymy after studying more material. The World Porifera Database also still treats T. latouchiana and T. paulula as separate species (van Soest et al. 2014), but careful comparison of spicules and gemmules of both the species under SEM, to settle this question, has not been attempted before and is urgently needed to validate the status of $T$. latouchiana fully. We are providing SEM pictures of $T$. latouchiana (collected from type locality), as a first step towards solving this problem and we hope similar work 
on T. paulula will settle it.

Recently, Pinheiro \& Nicacio (2012) have again raised the issue of genus Tubella Carter and have synonymised genus Trochospongilla with it. Because the World Porifera Database still lists Tubella as an invalid genus (van Soest et al. 2014), we have preferred to stick to the same generic name under which both the species were originally described, i.e., Trochospongilla.

Apart from $T$. latouchiana, Indian freshwaters harbour two other species of Trochospongilla, namely: T. phillottiana Annandale, 1907 (Annandale 1911; Penney \& Racek 1968) and T. pennsylvanica (Potts, 1882) (Annandale 1911).

T. phillottiana Annandale is originally described from Kolkata, India (Annandale 1907), and is also known to be found in tropical Asia, southern China, Philippines and doubtfully from Africa (Manconi \& Pronzato 2002). It has not been found elsewhere in India since its discovery (Annandale 1911; Soota 1991; Pattanayak 1998). The name of this species has been misspelled in literature after Annandale as ' $T$. philottiana' (Penney \& Racek 1968; Soota 1991; Pattanayak 1998; Manconi \& Pronzato 2002; van Soest et al. 2014). The name spelled by Annandale (1907) while describing the species is ' $T$. phillottiana'. In a recent paper, Manconi et al. (2013) have used this correct spelling. SEM studies on this species are also not available.

T. pennsylvanica (locality Travancore; Annandale 1909,1911 ) has apparently not been taken into account by Penney \& Racek (1968: who cited Annandale's papers), and Manconi \& Pronzato (2002). These authors have not included India as a locality for $T$. pennsylvanica and mention only N. America and treat Ireland \& Scotland as doubtful localities for distribution of this species. SEM studies on this species from India also are not available.

We feel that additional studies of Trochospongilla material from India and other localities are urgently needed to shed more light on the problems and solve some of the controversies mentioned above. Fresh collections and molecular methods may help to settle these discrepancies.

\section{REFERENCES}

Annandale, N. (1907). Notes on the Freshwater Fauna of India. No. IX. Descriptions of new Freshwater Sponges from Calcutta, with a record of two known species from the Himalayas and a list of the Indian forms. Journal and proceedings of the Asiatic Society of Bengal 3(1): 15-26.

Annandale, N. (1909). Notes on Freshwater Sponges. X. Report on a small collection from Travancore. Records of the Indian Museum 3: 101-104

Annandale, N. (1911). The Fauna of British India, including Ceylon and Burma. Freshwater Sponges, Hydroids and Polyzoa. Taylor and Francis, London, 251pp.

Annandale, N. (1919). Notes on Freshwater Sponges: A new race of Trochospongilla latouchiana from China. Records of the Indian Museum 16: 457-458.

Boury-Esnault, N. \& K. Rützler (1997). Thesaurus of Sponge Morphology. Smithsonian Contributions to Zoology (No. 596), 55pp.

Gee, N.G. (1932). The genus Trochospongilla of freshwater sponges. Peking Natural History Bulletin, 6(2): 1-32. (not seen in original)

Jakhalekar, S.S. \& H.V. Ghate (2013). A note on five freshwater sponges (Porifera: Spongillina: Spongillidae) from Pune, Maharashtra, India. Journal of Threatened Taxa 5(9): 4392-4403; http://dx.doi. org/10.11609/JoTT.03356.4392-403

Manconi, R. \& R. Pronzato (2002). Suborder Spongillina subord. nov.: Freshwater Sponges, pp. 921-1019. In: Hooper, J.N.A. \& R.W.M. van Soest (eds.). Systema Porifera: A Guide to the Classification of Sponges - Vol. 1. Kluwer Academic/Plenum Publishers, New York.

Manconi, R., N. Ruengsawang, V. Vannachak, C. Hanjavanit, N. Sangpradub \& R. Pronzato (2013). Biodiversity in South East Asia: an overview of freshwater sponges (Porifera: Demospongiae: Spongillina). Journal of Limnology 72(2s): 313-326; http://dx.doi. org/10.4081/jlimnol.2013.s2.e15

Masuda, Y. (2004). A study of the Freshwater Sponges, Eunapius carteri (Bowerbank, 1863), Eunapius crassissimus (Annandale, 1907), and Trochospongilla latouchiana Annandale, 1907, Spongillidae (Demospongiae) from Lake Tonle Sap in Cambodia. Kawasaki Medical Journal, Liberal Arts and Science Course 30: 47-62.

Masuda, Y. \& K. Satoh (1989). Scanning Electron Microscopic Observations on Spicules, Gemmule Coats, and Micropyles of the Freshwater Sponges Spongilla alba Carter, Eunapius coniferus (Annandale) and Trochospongilla latouchiana Annandale. Kawasaki Medical Journal, Liberal Arts and Science Course 15: 75-96.

Pattanayak, J.G. (1998). Freshwater Sponges, pp. 1-27. In: State Fauna Series 3: Fauna of West Bengal, part 11. Zoological Survey of India, Kolkata.

Penney, J.T. \& A.A. Racek (1968). Comprehensive revision of a worldwide collection of freshwater sponges (Porifera: Spongillidae). Bulletin of U.S. National Museum, No. 272, 184pp.

Pinheiro, U. \& G. Nicacio (2012). Resurrection and redefinition of the genus Tubella (Porifera: Spongillidae) with a worldwide list of valid species. Zootaxa 3269: 65-68.

Racek, A.A. (1969). The freshwater sponges of Australia (Porifera: Spongillidae). Australian Journal of Marine and Freshwater Research 20(3): 267-310.

Soota, T.D. (1991). Freshwater Sponges of India. Occasional Paper No. 138. Records of the Zoological Survey of India. Zoological Survey of India, Kolkata, 116pp.

van Soest, R.W.M., N. Boury-Esnault, J.N.A. Hooper, K. Rützler, N.J. de Voogd, B. Alvarez de Glasby, E. Hajdu, A.B. Pisera, R. Manconi, C. Schoenberg, D. Janussen, K.R. Tabachnick, M. Klautau, B. Picton, M. Kelly, J. Vacelet, M. Dohrmann, M.C. Díaz \& P. Cárdenas (2014). World Porifera database. Accessed at http://www.marinespecies. org/porifera on 2014-04-01. 